\title{
Uso de extrato de própolis como agente antisséptico para pré e pós dipping em vacas leiteiras
}

\section{Use of propolis extract as antisseptic agent for pre and post dipping on dairy cows}

\author{
Jeferson Lopes Schelles \\ Universidade Estadual de Maringá \\ E-mail: jefschelles@hotmail.com \\ OrcID: https://orcid.org/0000-0003-4469-0798
}

Bruna Moura Rodrigues

Universidade Estadual de Maringá

E-mail: bmrodrigues@live.com

OrcID: https://orcid.org/0000-0001-6613-6689

Magali Soares dos Santos Pozza

Universidade Estadual de Maringá

E-mail: pozzamagali@yahoo.com.br

OrcID: https://orcid.org/0000-0002-3500-1914

Luciano Soares de Lima

Universidade Federal de Minas Gerais

E-mail: luciano.delima@hotmail.com

OrclD: https://orcid.org/0000-0003-1437-4591

Resumo: A realização de pré e pós dipping visam reduzir bactérias nos tetos, evitando mastite e o uso de antibióticos. Avaliou-se a utilização de extrato alcoólico de própolis em comparação a um produto I a base de iodo para pré e pós dipping. Utilizaram-se 12 vacas leiteiras, multíparas, mestiças, utilizando o delineamento experimental delineamento em parcelas subdivididas, (1) controle, utilizando-se produto à base de iodo (2) utilização do extrato alcoólico de própolis. O experimento teve duração de 28 dias, com amostras de leite coletadas semanalmente. Não houve $(P>0,05)$ efeito dos tratamentos sobre a concentração de proteína, lactose, gordura e contagem de células somáticas. $O$ extrato de própolis reduziu $(P=0,0036)$ a carga microbiana nos tetos. $O$ extrato de própolis pode ser usado como agente desinfetante para os tetos de vacas leiteiras em substituição à solução de iodo propiciando semelhantes características qualitativas no leite, com redução microbiana dos tetos.

Palavras-Chave: lodo. Mastite. Microrganismos. Ordenha.

Abstract: Pre and post dipping are aimed at reducing bacteria on the ceilings, avoiding mastitis and the use of antibiotics. In this study, the use of alcoholic propolis extract was compared to a commercial product based on iodine for pre and post dipping. Twelve dairy cows, multiparous, crossbred, were used, using the experimental design delineated in split plots, with the treatments (1) control group, being used in the animals an iodinebased product (2) animals that received alcoholic propolis extract. The experiment lasted 28 days, with milk samples collected weekly. There was no $(P>0.05)$ effect of treatments on the concentration of protein, lactose, fat and somatic cell count. The propolis extract reduced $(P=0.0036)$ the microbial load on the teats and can be used as a disinfectant agent for dairy cows to replace the iodine solution, providing similar qualitative characteristics in milk, with microbial reduction of the teats.

Keywords: lodine. Mastitis. Microorganisms. Milking. 


\section{Introdução}

Uma preocupação mundial está relacionada com a alimentação, onde os consumidores têm demonstrado muito interesse na qualidade dos produtos consumidos tanto de origem animal quanto vegetal. Com isto, os produtores são geralmente desafiados a fazer ajustes em suas práticas com objetivo de melhorar ou manter a qualidade dos produtos (Peixoto, Garcia, Domingues \& Orsi. 2009).

Para garantir a qualidade do leite, os produtores devem assegurar que o produto apresente as características previstas na Instrução Normativa 76 (IN 76) quanto a contagem de células somáticas (CCS), contagem bacteriana total (CBT), sólidos totais, gordura, proteína, lactose e minerais, sabor, odor e aparência (Brasil, 2018).

Um dos problemas que mais afetam a qualidade e a produção de leite é a mastite, inflamação das glândulas mamárias, normalmente, com origem infecciosa que causa sérios prejuízos ao sistema produtivo, pois diminui a longevidade do animal e também a sua vida produtiva (Menezes et al. 2015)

Segundo Andrade (2010), o uso de antibióticos indiscriminado é o procedimento mais utilizado pelos produtores no tratamento da mastite bovina, com isso ocorre aumento da preocupação da sociedade com a presença de resíduos de antibióticos no leite, pois, a administração de antimicrobianos alopáticos convencionais para o tratamento de mastite clínica (oxitetraciclina, gentamicina, sulfadoxina, trimetoprim, dentre outras), podem causar sérios problemas a saúde humana e também animal, podendo levar ao surgimento de bactérias resistentes aos princípios ativos mais utilizados. Isto tem estimulado a busca por meios alternativos e naturais que reduzam ou eliminem tais problemas.

Uma forma de prevenção deste problema é o uso do pré e pós dipping durante a ordenha, isso faz com que a carga de micro-organismos nos tetos seja reduzida consideravelmente. Todavia, os produtos utilizados para execução de pré e pós dipping, por exemplo, produtos a base de iodo, por sua vez, também podem deixar resíduos no leite quando não utilizados de forma correta (Lopes, Lacerda \& Ronda, 2013). O iodo no organismo humano em doses adequadas previne o aparecimento do bócio que é o crescimento exagerado da glândula tireoide, também é essencial para o adequado funcionamento da tireoide. Por outro lado, o iodo em grandes quantidades, pode ser tóxico e causar problemas de saúde tanto para o homem como para os animais, um dos problemas pode ser a Tireoidite Crônica Autoimune, conhecida também por Tireoidite de Hashimoto (WHO, 2007).

Devido a esses e muitos outros efeitos nocivos à saúde humana, uma forma de evitá-los é utilizando produtos $100 \%$ naturais para a realização do pré e pós dipping, pois, são de fácil utilização, não apresentam toxidade, não deixam resíduos no leite, possuem baixo custo e são fáceis de encontrar na natureza. Um produto que se adéqua a essas características é a própolis (Coutinho et al. 2012).

A própolis é um produto elaborado a partir da coleta de resinas de plantas e ceras. A resina normalmente é coletada nas cascas das árvores, podendo ser também encontrada nas gemas apicais, brotos, flores e exsudados de plantas e até nas folhas de alguns vegetais. A própolis é composta basicamente por $55 \%$ de resinas e bálsamos, $30 \%$ de cera, $10 \%$ de óleos voláteis e $5 \%$ de pólen, sendo que sua composição pode variar devido a sua origem. A própolis age como desinfetante, bactericida, bacteriostáticas, antifúngicas, analgésicas, cicatrizantes, anti-inflamatórias, anestésicas, antioxidantes dentre outras (Couto \& Couto, 2006).

Assim, o trabalho foi realizado com o objetivo de avaliar o efeito da utilização de extrato alcoólico de própolis em comparação a produtos convencionais (a base de iodo), na realização do pré e pós dipping em vacas leiteiras sobre a carga microbiana da superfície dos tetos e sobre a qualidade do leite.

\section{Material e Métodos}

Os procedimentos experimentais foram previamente aprovados pela Comissão de Ética no Uso de Animais (CEUA), da Universidade Estadual de Maringá (UEM), sob protocolo $n^{\circ} 5771200818$.

O experimento foi realizado na Chácara Schelles, Iguaraçú/PR, utilizando-se 12 vacas leiteiras, multíparas, mestiças (Jersey $\times$ Holandês), com peso corporal médio de $400 \pm 120 \mathrm{~kg}$ e produção média total de 132 litros de leite por dia, mantidas em pastagem de grama Estrela Africana (Cynodon plectostachyus) e receberam suplementação com $60 \%$ silagem de sorgo e $40 \%$ concentrado contendo $20 \%$ de proteína bruta.

Os animais foram divididos em dois grupos experimentais, utilizando o delineamento experimental delineamento em parcelas subdivididas: (1) grupo controle, realização de pré e pós dipping com produto convencional à base de iodo e, (2) realização de pré e pós dipping com extrato alcoólico de própolis. Para utilização do antisséptico iodado de uso convencional (com $0,60 \%$ de concentração de iodo ativo), em pré 
dipping, utilizou-se diluição em água na proporção de 1:5 (v/v), enquanto para pós dipping a solução a base de iodo foi utilizada pura. Para o extrato de própolis a 35\% em álcool de cereais, utilizou-se diluição em água de 1:20 (v/v). Os animais selecionados não foram medicados com antibióticos nos sete dias que antecederam a realização do experimento, para que possíveis interferências nos resultados fossem evitadas.

O período experimental teve duração de 28 dias, sendo 7 dias para adaptação aos tratamentos experimentais e durante esse período e em todo o experimento, os animais não foram medicados, vermifugados ou sofreram algum tipo de manejo diferente da rotina de ordenha.

As amostras de leite foram coletadas das ordenhas da manhã e tarde (proporcao70:30, de acordo com a produção dos animais) nos dias 7, 14, 21 e 28 após as práticas de pré e pós dipping. Estas foram coletadas individuais, em um recipiente limpo, homogeneizadas e armazenadas separadamente em duas alíquotas. A primeira alíquota de cada amostra foi acondicionada em frasco plástico, contendo conservante Bronopol (2bromo-2-nitro-1,3-propanodiol), e armazenada a $4{ }^{\circ} \mathrm{C}$ para posteriores análises químicas no laboratório de análise de leite do Centro Mesorregional de Excelência em Tecnologia do Leite - Noroeste, localizado na Fazenda Experimental de Iguatemi (FEI), pertencente a Universidade Estadual de Maringá (UEM). As amostras foram analisadas quanto aos teores de proteína, lactose, gordura e contagem de células somáticas (CCS) em Ecomilk Total e Ecomilk Scan, respectivamente. A segunda alíquota de cada amostra foi armazenada em frasco plástico sem conservante e utilizada para a avaliação de microrganismos mesófilos.

A contagem de microrganismos aeróbios mesófilos na superfície dos tetos foi determinada por meio de coleta por Swabs (3M ${ }^{\mathrm{TM}}$ Quick Swabs) nos quatro tetos de cada animal nos dias 7, 14, 21 e 28, antes e após o pré-dipping. As amostras foram armazenadas em tubos de ensaio estéreis, com tampa, contendo 9 $\mathrm{mL}$ de água peptonada estéril, para posterior avaliação de microrganismos aeróbios mesófilos.

Para análise microbiológica do leite e dos Swabs, utilizou-se Agar PCA (Plate Count Agar- DIFCOß), onde realizou-se diluições seriadas das amostras em tubos de ensaio contendo $9 \mathrm{~mL}$ de água peptonada, semeadas por profundidade em placas de Petri, e então as amostras foram incubadas a $32^{\circ} \mathrm{C}$ por 48 horas, em condições de aerobiose para posterior contagem de microrganismos.

Os dados foram analisados em delineamento em parcelas subdivididas com medidas repetidas por meio do procedimento ANOVA do SAS (SAS, 2000; SAS Institute) de acordo com o seguinte modelo:

$$
Y_{i j k}=\mu+T_{i}+e_{i j}+P_{k}+T P_{i k}+d_{i j k}
$$

Em que: Yijk= Observação na medida $k$, da repetição $\mathrm{j}$ e do tratamento $\mathrm{i} ; \mu=$ constante associada a todas as observações; $T_{i}=$ efeito do tratamento $i ;(i=1, \ldots l) ; e_{i j}=$ erro aleatório $(A)$, associado à parcela; $(j=1, \ldots J) ; P_{k}=$ efeito do período de coleta $\mathrm{k} ;(\mathrm{k}=1, \ldots \mathrm{K})$; $\mathrm{TP}_{\mathrm{ik}}=$ efeito da interação do tratamento i com o período de coleta $\mathrm{k}$; $\mathrm{D}_{\mathrm{ijk}}=$ erro aleatório $(\mathrm{B})$, associado à subparcela.

Para avaliação dos efeitos estudados foi estabelecido o grau de significância estatística em P $\leq 0,05$.

\section{Resultados e Discussão}

Não foi verificada diferença $(P>0,05)$ entre os tratamentos sobre a concentração de proteína, lactose e gordura no leite (Tabela 1), pois segundo Santos e Guerios (2020), dentre vários fatores, os principais determinantes para as proporções destes sólidos são a dieta, sanidade, manejo de ordenha, estação do ano, estágio de lactação, genética e raça. Os dados das contagens microbiológicas obtidos nos swabs, sugerem que o extrato de própolis foi efetivo em manter a saúde da glândula mamária prevenindo sua contaminação.

Tabela 1. Composição do leite, contagem de células somáticas (CCS) e contagens microbiológicas do leite e tetos de vacas mestiças submetidas ao tratamento com iodo e própolis.

\begin{tabular}{lllll}
\hline & \multicolumn{2}{l}{ Tratamento } & & \\
\cline { 2 - 3 } Item & Controle & Própolis & EPM ${ }^{1}$ & $\mathrm{P}^{2}$ \\
\hline Composição do leite $(\mathrm{kg} / \mathrm{d})$ & & 3,38 & 0,026 & 0,4000 \\
$\quad$ Proteína & 3,59 & 3,43 & 0,054 & 0,7300 \\
$\quad$ Gordura & 4,08 & 4,14 & 0,039 & 0,4800 \\
$\quad$ Lactose & 8,06 & 8,18 & 0,071 & 0,4500 \\
$\quad$ Extrato Seco Desengordurado & 1,97 & 2,00 & 0,014 & 0,1400 \\
Contagem de células somáticas $(\log 10 / \mathrm{mL})$ & $3,08^{\mathrm{a}}$ & $2,73^{\mathrm{b}}$ & 0,074 & 0,0036 \\
Swab antes Pré-Dipping $(\log 10 / \mathrm{mL})$ & 2,21 & 2,12 & 0,078 & 0,5100 \\
Swab após Pré-Dipping $(\log 10 / \mathrm{mL})$ & & & &
\end{tabular}


Infecções intramamárias têm sido documentadas como fator causador de alterações na composição do leite, embora tal efeito não tenha sido verificado no presente estudo. Em estudo Pelegrino, Mello e Amaral (2008), identificaram que quando ocorre o aumento da contagem de células somáticas (CCS) no leite, há diminuição da lactose, gordura, caseína e sólidos totais, por outro lado há aumento dos níveis de sódio, cloro e proteínas séricas. Em vacas com mastite, observa-se uma lesão do epitélio glandular, a qual pode levar a uma diminuição dos componentes sintetizados no interior da glândula, especialmente a caseína, o que explica a diminuição no percentual de proteína e gordura do leite com alta CCS. No entanto, quando a diminuição da produção ocorre de maneira mais acentuada que a síntese, o teor de gordura sofre aumento proporcional (Machado, Pereira \& Sarríes, 2000). O aumento na contagem de células somáticas (CCS) provoca queda na produtividade, além de influenciar na composição do leite, na atividade enzimática, tempo de coagulação, rendimento e qualidade dos derivados lácteos (Montanhini, Moraes \& Neto, 2013).

Coelho et al. (2014) avaliaram a produção de queijo muçarela produzido com culturas termofilias e por Mattielo et al. (2018) ao produzirem queijo colonial, ambos obtiveram menor rendimento nos queijos, fato devido ao menor teor de sólidos no leite, além de perda de proteína e gordura do leite para o soro. Em leite com alta CCS, pode ocorrer a inibição da cultura láctica adicionada pelos fatores inibidores produzidos pelos leucócitos presentes, o que impede a alteração do $\mathrm{pH}$ da massa de queijo (processo necessário para a adequada sinérese da massa), resultando em queijos com maior teor de umidade o que aumenta a atividade de água para os microrganismos e pode, portanto, reduzir a vida de prateleira desses produtos, devido à deterioração precoce (Mazal, Vianna, Santos \& Gigante, 2007).

As análises de swabs mostraram que o extrato de própolis reduziu $(P=0,0036)$ a carga microbiana nos tetos das vacas na avaliação antes da realização do pré-dipping (Tabela 1). Isto sugere que o extrato de própolis obteve efeito antimicrobiano mais duradouro em comparação à solução de iodo quando aplicado em pós-dipping, mantendo menor a contagem de microrganismos de uma ordenha para a outra. No entanto, quando o teste foi realizado após o pré-dipping não houve diferença entre os tratamentos (Tabela 1). Costa, Andrea, Carvalho, Almeida e Ledo. (2011) também não observaram diferença para o CMT de vacas com mastite subclínica com o uso de solução hidroalcoólica de própolis em diferentes concentrações (12\%, 20\% e $30 \%)$ e o tratamento testemunha (100\% álcool de cereais) durante 72 horas.

Entretanto, pesquisas conduzidas por Andrade (2010) utilizando iodo e extrato de própolis na imersão dos tetos, ambos os tratamentos apresentaram redução do Log UFC/ $\mathrm{cm}^{2}$, a redução do $\mathrm{Log} \mathrm{UFC} / \mathrm{cm}^{2}$ da préimersão dos tetos e Log UFC/ $\mathrm{cm}^{2}$ para pós imersão dos tetos em função do efeito de tratamento contendo iodo glicerinado $0,5 \%$ foi de $31,3 \%\left(3,54 \mathrm{Log} \mathrm{UFC} / \mathrm{cm}^{2}\right.$ para $\left.2,43 \mathrm{Log} \mathrm{UFC} / \mathrm{cm}^{2}\right)$ e para o tratamento contendo extrato de própolis, foi de $30,1 \%\left(3,61 \mathrm{Log}\right.$ UFC/cm 2 para $\left.2,52 \mathrm{Log} \mathrm{UFC} / \mathrm{cm}^{2}\right)$.

De fato, a própolis possui diversos compostos com ação antimicrobiana, destacando como mais importantes, os aldeídos fenólicos, ácidos fenólicos, ésteres, cetonas e flavonoides (Júnior et al. 2006). Em estudo in vitro Pinto et al. (2001), observaram que o extrato etanólico de própolis foi eficaz no controle dos microrganismos mais comuns causadores de mastite bovina (Staphylococussus aureus, Staphylococcus sp. coagulase negativa e Streptococcus agalactiae). Um outro estudo realizado por Bastos, Galbiati, Loureiro e Scoaris (2010), foi observado que extratos de própolis marrom, apresentaram ação antibacteriana em exposição a Escherichia coli, bactéria bacilar Gram-negativo.

A qualidade microbiológica do leite não foi alterada conforme sugerido pelos resultados da análise de contagem de mesófilos aeróbios, estando em conformidade com a legislação vigente, a qual deverá ser no máximo de $\log _{10} 5,47$ para CBT (contagem bacteriana total) (IN 76). Em estudos conduzidos por Nero, Viçosa e Pereira (2009), os autores verificaram que produtores que adotavam medidas higiênicas na ordenha, obtiveram resultados menores de aeróbios mesófilos no leite e com isso um produto de melhor qualidade, sendo necessário também um bom sistema de resfriamento do leite. Segundo Matsubara et al. (2010), os microrganismos psicrotróficos, aeróbios mesófilos, estafilococos coagulase positivos (ECP), Escherichia coli (EC) e coliformes totais (CT) são os mais importantes indicadores para avaliar a qualidade do leite.

De forma geral, estes dados sugerem que o extrato de própolis foi efetivo em manter a saúde da glândula mamária, pois manteve níveis de CCS abaixo da legislação em vigor (máximo de 5,69 $\log _{10}$ ), a semelhante qualidade microbiológica e físico-química do leite quando comparado com a solução de iodo comumente utilizada para assepsia dos tetos de vacas leiteiras. Entretanto, as variáveis teor de lactose (min de $4,3 \%$ ) e SNG (min 8,4\%) estavam abaixo da legislação em vigor. 


\section{Conclusão}

O extrato de própolis pode ser usado como agente desinfetante para os tetos de vacas leiteiras em substituição à solução de iodo, propiciando semelhantes características físico-químicas e microbiológicas no leite, com redução da carga microbiana nos tetos.

\section{Referências}

Andrade, U.V.C. (2010). Potencial antibacteriano do extrato de Hidrossolúvel de própolis obtido por hidrólise alcalina para a inibição de cultivo de Staphylococcus aureus e higienização de pré e pós - imersão de tetos de vacas leiteiras.100 f. Tese (Doutorado em Tecnologia de alimentos) - Universidade Federal do Paraná.

Bastos, E.M.F.; Galbiati, E.M.; Loureiro, Scoaris, D.O. (2011). Indicadores físico-químicos e atividade antibacteriana de própolis marrom frente à Escherichia coli. Arquivo Brasileiro de Medicina Veterinária e Zootecnia, v.63, n.5, p.1255-1259. doi.org/10.1590/S0102-09352011000500032

BRASIL. Ministério da Agricultura, Pecuária e Abastecimento. Instrução normativa $n^{\circ} 76$, de 26 de novembro de 2018. Regulamentos Técnicos que fixam a identidade e as características de qualidade que devem apresentar o leite cru refrigerado, o leite pasteurizado e o leite pasteurizado tipo A. Diário Oficial da União, Brasília, 2018.

Coelho, K.O.; Mesquita, A.J.; Machado, P.F.; Lage, M.E.; Meyer, P.M., Reis, A.P (2010). Efeito da contagem de células somáticas sobre o rendimento e a composição físico-química do queijo muçarela. Arquivo Brasileiro de Medicina Veterinária e Zootecnia, v.66, n.4, p.1260-1268. dx.doi.org/10.1590/1678-7616

Costa, C.N., Andrea, M.V., Carvalho, G.J.L., Almeida, A.M.L., Ledo, C.A.S (2011) Avaliação do efeito do extrato de própolis no tratamento da mastite subclínica em vacas de leite. Magistra, Cruz das Almas, v. 23, n. 4, p. 257-261.

Coutinho, L.C.A.; Medeiros, E.S.; Silveira, N.S.S.; Silva, L.B.G., Mota, R.A. (2012). Eficácia in vitro de desinfetantes utilizados na anti-sepsia dos tetos frente a leveduras isoladas do leite de vaca com mastite. Pesquisa Veterinária Brasileira, v. 32, n. 1, p. 61-65. dx.doi.org/10.1590/S0100-736X2012000100010.

Couto, N.H.R., Couto, A.L. (2006). Apicultura: Manejo e produtos. $3^{\circ}$ ed. Jaboticabal: FUNEP;193 p.

Júnior, A.F.; Lopes, M.M.R.; Colombari, V.; Monteiro, A.C.M., Vieira, E.P (2006) Atividade antimicrobiana de própolis de Apis mellifera obtidas em três regiões do Brasil. Ciência Rural, v.36, n.1, p. 294-297. doi.org/10.1590/S0103-84782006000100047

Lopes, L.O.; Lacerda, M.S., Ronda, J.B. (2013) Eficiência de desinfetantes em manejo de ordenha em vacas leiteiras na prevenção de mastite. Revista Cientifica Eletrônica de Medicina Veterinária, n.21.

Machado, P.F.; Pereira, A.R., Sarríes, G.A. (2000) Composição do leite de tanques de rebanhos brasileiros distribuídos segundo sua contagem de células somáticas. Revista Brasileira de Zootecnia, v.29, p.1883-1886. doi.org/10.1590/S1516-35982000000600038.

Matsubara, M.T.; Beloti, V.; Tamanini, R.; Fagnani, R.; Silva, L.C.C.; Monteiro, A.A.; Battaglini, A.P.P.; Ortolani, M.B.T.; Barros, M.A.F (2010). Boas práticas de ordenha para redução da contaminação microbiológica do leite no agreste Pernambucano. Semina: Ciências Agrárias, v.32, n.1, p. 277-286. doi.org/10.5433/1679-0359.2011v32n1p277

Mattiello, C.A., Silveira, S.M., Carli, F., Junior, A.C., Alessio, D.R.M., Pelizza, A., Cardozo, L.L., Neto, A.T. (2018). Rendimento industrial, eficiência de fabricação e características físico-químicas de queijo colonial produzido de leite com dois níveis de células somáticas. Arquivo Brasileiro de Medicina Veterinária e Zootecnia, v. 70, n. 6. dx.doi.org/10.1590/1678-4162-9908.

Mazal, G.; Vianna, P.C.B.; Santos, M.V., Gigante, M.L (2007). Effect of somatic cell count on prato cheese composition. Journal Dairy Science, v.90, p.630-636. doi.org/10.3168 / jds.S0022-0302 (07) 71545-X.

Menezes, I.R.; Almeida, A.C.; Morão, R.P.; Reis, S.V.; Santos, C.A. Lopes, I.L.N. (2015). Qualidade microbiológica do leite cru produzido no Norte de Minas Gerais. Revista Brasileira de Ciência Veterinária. v. 22 , n. 1, p. 58-63. doi.editoracubo.com.br/10.4322/rbcv.2015.321 
Montanhini, M.T., Moraes, D.H.M., Neto, R.M (2013). Influência da contagem de células somáticas sobre os componentes do leite. Revista do Instituto de Laticínios Cândido Tostes, v. 68, n. 392, p. 18-22. doi.org/10.5935/2238-6416.20130024

Nero, L.A.; Viçosa, G.N.; Pereira, F.E.V. (2009). Qualidade microbiológica do leite determinada por características de produção. Ciência e Tecnologia de Alimentos, v.29, n.2, p. 386-390. 10.1590/S010120612009000200024

Peixoto, E.C.T.M.; Garcia, R.C.; Domingues, P.F., Orsi, R.O (2009). Utilização da própolis na saúde animal. Scientia Agraria Paranaensis. v. 8, n. 1-2, p. 5-24. doi.org/10.18188/sap.v8i1.3828

Pelegrino, R.C.; Mello, F.C., Amaral, G.A.C. (2008). Mastite em vacas leiteiras. Revista Científica Eletrônica de Medicina Veterinária, n.10.

Pinto, M.S.; Faria, J.E.; Message, D.; Cassini, S.T.A.; Pereira, C.S.; Gioso, M.M. (2001). Efeito de extratos de própolis verde sobre bactérias patogênicas. Brazilian Journal of Veterinary Research and Animal Science, v.38, n.6, p. 278-283. dx.doi.org/10.1590/S1413-95962001000600006.

Santos, J.H.A., Guerios, E.M.A. (2020). Principais fatores que influenciam na concentração de sólidos totais no leite de fêmeas bovinas. Arquivos Brasileiros de Medicina Veterinária, v. 3, n. 1, p. 81-88.

WORLD HEALTH ORGANIZATION (WHO). Assessment of iodine deficiency disorders and monitoring their elimination. Geneva, 2007. 